\title{
Mortality in individuals who have had psychiatric treatment
}

\author{
Population-based study in Nova Scotia \\ STEPHEN KISELY, MARK SMITH, DAVID LAWRENCE and SARAH MAATEN
}

\begin{abstract}
Background Most studies of mortality in psychiatric patients have investigated inpatients rather than those attending outpatient clinics or primary care, where most receive treatment.
\end{abstract}

\begin{abstract}
Aims To evaluate the mortality risk in mental illness for patients in contact with psychiatric services or primary care $(n=221048)$ across Nova Scotia (population 936 025).
\end{abstract}

\section{Method Apopulation-based record- linkage analysis was made of the period 1995-2000, using an inception cohort to calculate mortality rate ratios.}

Results The mortality rate was 1.74 , with increased ratios for all major causes of death. Male mortality was almost double that of females after controlling for demographic factors, treatment setting and place of residence. Patients of lower income, in specialist psychiatric settings, and with dementia or psychoses were also at greater risk. However, in absolute numbers, $72 \%$ of deaths occurred in patients who had only seen their general practitioner.

\section{Conclusions Mortality risk is} increased in all psychiatric patients, not just those who have received in-patient treatment.

Declaration of interest None. Funding detailed in Acknowledgement.
Studies of the high mortality rates among people with psychiatric disorders have generally been restricted to patients of specialised mental health services (Lawrence et al, 2000, 2003; Brown et al, 2000; Hannerz et al, 2001; Rasanen et al, 2003; Vythilingam et al, 2003). Long-stay psychiatric in-patients have the greatest mortality risk (Rasanen et al, 2003). However, the variation between health systems in different countries makes comparison difficult. Surveys of patients attending primary care (Ensinck et al, 2002), or community-based surveys (Mulsant \& Ganguli, 1999; Ostbye et al, 1999) are subject to less referral bias, but are expensive to conduct and limited to the more common psychiatric conditions such as depression, anxiety and dementia. Results from these surveys confirm similar but less marked increases in mortality rates.

\section{METHOD}

\section{Data sources}

We evaluated the association between mortality and psychiatric disorder for all patients of specialist services and primary care across Nova Scotia, using the province's linked administrative databases. The 1 million residents of this province have similar morbidity and mortality rates to the rest of the country, although more live in rural areas. Halifax is the major metropolitan centre.

Under the Canada Health Act 1984, all Canadian residents are entitled to in-patient or out-patient care that is free at the point of delivery. Patients receive treatment at publicly funded facilities or are seen by private psychiatrists or general practitioners in the community, who then bill the provincial health plan. However, the provincial health plan does not cover visits to private psychologists or other mental health professionals in private practice. There are no private psychiatric beds. Our linked administrative databases therefore cover health service use in the public and private sectors across the whole province, including in-patient, out-patient and community contacts with both specialist services and primary care. We used the following anonymised databases to identify patients for our study:

(a) The Medical Services Insurance Physician Services database, which records all fee-for-service claims by physicians including date of service, specialty, diagnosis (ICD-9) and patient demographics. This covers all family physicians and private psychiatrists.

(b) The Discharge Abstract Database, which includes demographic and diagnostic details of all hospital admissions in Canada.

(c) The Mental Health Outpatient Information System, which records demographic data, diagnoses and outpatient attendances in the public sector.

We measured mortality rates using the Canadian Vital Statistics Database, calculated using the inception cohort method. We restricted the cohort to patients whose first psychiatric contact occurred between 1995 and 2000. Follow-up started at the date of first contact. Patients were censored at death. This method has greater validity as all the follow-up time at risk is included, thereby reducing survivorship bias. The ethics committee of Capital District Health Authority approved the protocol.

The validity of the Discharge Abstract Database has been evaluated in seven reabstraction studies and been found to have an accuracy rate of $97-99 \%$ for in-patient demographic data, including gender, age, treating physician, admission and discharge dates, and discharge destination (Ontario Hospital Association et al, 1991; Williams $\&$ Young, 1996). Information on the validity of other administrative data is more limited (Kephart et al, 2003), but there are precedents in other parts of Canada for the use of data on health service use and physician billings in the study of chronic illness (Clottey et al, 2001; Strom, 2001). Finally, although the administrative databases use ICD-9 diagnoses (World Health Organization, 1978), mental health clinicians make their diagnoses using the Diagnostic and Statistical Manual of Mental Disorders (DSM-IV; American Psychiatric Association, 1994). Mental health professionals in publicly funded facilities also attend DSM training courses to improve diagnostic accuracy. These DSM 
diagnoses are converted to ICD-9 codes using a conversion table.

\section{Classification of mental disorders}

We used the method developed by Lawrence et al (2000) to group cases in terms of severity of diagnosis. We used the final diagnosis in each episode of care, and gave preference to diagnoses made in hospital care over out-patient or primary care.

We grouped disorders into dementia and other organic conditions (ICD-9 codes 290-294), functional psychoses (schizophrenia and non-affective psychoses, ICD9 codes 295, 297-299 except 298.0), alcohol and drug disorders (ICD-9 303$305)$, mood disorders (affective psychoses, ICD-9 296; reactive depressive psychosis, ICD-9 298.0; neurotic depression, ICD-9 300.4; depression not otherwise specified, ICD-9 311), neuroses (ICD-9 300 except 300.4), personality disorders (ICD-9 301), adjustment reactions (ICD-9 308-309), other mental disorders (all remaining Chapter 5 diagnoses and non-specific diagnoses outside Chapter 5). We did not include non-Chapter 5 diagnoses of patients only attending primary care, as they would not necessarily be psychiatric. However, we included non-Chapter 5 diagnoses in patients of specialist services, because referral to psychiatric services implied some psychiatric morbidity. This method ensured comparability with previous Australian work that also included non-Chapter 5 diagnoses (Lawrence et al, 2000). We did undertake a sensitivity analysis of excluding the non-Chapter 5 'mental disorders' diagnoses in the specialist group.

\section{Calculation rates}

We calculated age-adjusted and genderadjusted mortality rates using direct standardisation. Average population distributions in Nova Scotia from 1995 to 2000 inclusive were used as the standard weights. The follow-up period began on the date of the patient's first contact with a clinician. We censored patients at death or on 31 December 2000. Rates were calculated by principal diagnosis by type of care received and cause of death. Mortality rates were also calculated in the rest of the Nova Scotian population by cause of death and gender. Denominators were taken from estimated resident population counts. Mortality rate ratios were calculated in the study cohort relative to the rate in the province's population. We compared a direct standardised mortality rate by psychiatric diagnosis, cause of death, diagnostic case complexity and treatment setting. We used a hierarchy of in-patient $v$. out-patient and specialist $v$. primary care, reflecting both the increasing proportion of patients with severe mental illness and data reliability. It also allowed comparison with Australian data (Lawrence et al, 2000).

\section{Regression analysis}

We used proportional hazards regression to examine the risk of death from time of first contact for psychiatric disorder until death or censoring at the end of follow-up (31 December 2000). We included principal psychiatric diagnosis, age (in 10-year increments), gender, socio-economic status, treatment setting and place of residence (metropolitan Halifax or elsewhere in the province). Socio-economic status was assigned according to the 1996 censusderived average household income by residential postcode (Kapral et al, 2002). Income levels of the study population were classified into the quartiles of the 1996 census average household income by postal code to the 1999 Nova Scotian population (we used the address recorded at the time of the initial contact). All analyses were completed using SAS version 8 .

\section{RESULTS}

\section{Overall mortality}

There were 221048 patients recorded on the linked database between 1995 and 2000. These consisted of 68101 patients who had been treated in specialist services and 152947 patients who had only been seen in primary care. Of all these patients, 8917 (4\%) died during the period: 2504 who had been treated in specialist settings and 6413 who had only been treated in primary care. The overall age-standardised mortality rate was 1394 per 100000 person years (95\% CI 1360-1420), compared with a mortality rate among the rest of the Nova Scotian population of 799 per 100000 person years (95\% CI 791-806). For males, the age-standardised mortality rate was 1505 per 100000 person years $(95 \%$ CI 1460-1550); for females, it was 1286 per 100000 person years (95\% CI 1250 1320). This was statistically greater than the mortality rate in the rest of the Nova Scotian population of 835 per 100000 person years for males (95\% CI 824-846) and 763 per 100000 person years for females (95\% CI 753-774). These figures translated into a mortality rate ratio of 1.74 overall, 1.80 for males and 1.69 for females.

\section{Specialist psychiatric settings}

Mortality rate ratios were particularly high for patients who had been treated in specialist services (Table 1). Within the specialist group, mortality rates were similar in people who had received in-patient, out-patient and private specialist treatment in the community (Table 1). Males had significantly higher mortality rate ratios than females in in-patient and out-patient settings, but not among those attending private specialists, where the reverse was true (Table 1).

The mortality rate ratio was significantly greater than 1 for all psychiatric diagnoses in both genders, with the exception of males with a diagnosis of neurotic disorder, and females with personality disorder (Table 2). Rates were highest for patients with dementia and other psychoses (Table 2). Mortality rate ratios were also significantly greater than 1 for all causes, in both males and females, with the highest rate being for suicide (Table 3 ).

\section{Primary care}

The mortality rate ratio for both men and women with psychiatric diagnoses was significantly higher than that of the general population, but lower than for patients in specialist settings (see Table 2). It was significantly greater than 1 for all psychiatric diagnoses in both genders, except for schizophrenia and neurotic and personality disorders, and in females with a diagnosis of alcohol, drug or adjustment disorders. The small number of people with schizophrenia, indicated by the wide confidence intervals, may explain the negative results for schizophrenia. Mortality rate ratios were also significantly greater than 1 for all causes of death except for diabetes in both genders, myocardial infarction in males and suicide in females (see Table 3). Unlike patients in specialist settings, suicide did not have the highest mortality rate ratio.

\section{All settings}

When we combined the results from specialist and primary care settings, all psychiatric disorders were associated with significantly higher mortality except for alcohol or drug disorders and neurotic 
Table I Mortality rate ratios of patients treated in specialist services and primary care

\begin{tabular}{lccc}
\hline & \multicolumn{1}{c}{ Males } & & Females \\
\cline { 2 - 2 } & MRR $(95 \% \mathrm{Cl})$ & & MRR $(95 \% \mathrm{Cl})$ \\
\hline Specialist services & & \\
$\quad$ In-patients & $3.07(2.72-3.42)$ & & $2.13(1.81-2.45)$ \\
Out-patients & $2.63(2.48-2.79)$ & & $2.41(2.27-2.55)$ \\
Private specialists & $2.94(2.72-3.16)$ & & $3.19(2.96-3.41)$ \\
$\quad$ Total specialist services & $2.78(2.67-2.88)$ & & $2.60(2.50-2.69)$ \\
General practice & $1.54(1.50-1.57)$ & & $1.43(1.39-1.46)$ \\
\hline
\end{tabular}

MRR, mortality rate ratio.

disorders in females (see Table 2). Mortality rate ratios were also significantly greater than 1 for all causes of death (see Table 3). A sensitivity analysis revealed that mortality rate ratios for men and women were virtually unchanged after removing suicide as a cause of death. The total mortality rate ratio was 1.74 (95\% CI 1.72-1.76); after removing suicide as a cause of death, the ratio was 1.72 (95\% CI 1.69-1.74).

\section{Predictors of mortality}

We used Cox regression to calculate relative risks for mortality, adjusting for confounders such as age, gender and income (Table 4). The risk of mortality was $75 \%$ higher in males than in females. Although patients with dementia and other psychoses were at highest risk across diagnostic groups, mortality risk was elevated for all psychiatric disorders. Patients in specialist psychiatric settings were significantly more likely to die. Within the group of patients attending specialist psychiatric services, people receiving out-patient treatment in the public sector had a significantly lower risk than those treated as in-patients or those attending private specialists. There was no significant difference in the mortality risk between in-patients and those attending private

A similar pattern was seen for specific causes of death (Table 5). Male gender, greater age and lower income were generally associated with increased mortality risks. Dementia, other psychoses or specialists. depression were the psychiatric diagnoses most frequently associated with significantly increased mortality from cancer, diabetes, heart disease or cerebrovascular disease. As seen in the analysis of overall mortality, patients attending specialist settings had a higher relative risk than those attending primary care, out-patients in the public sector having a significantly lower risk than in-patients or those attending private specialists (Table 5). See Tables 6-10 (presented as a data supplement to the online version of this paper) for additional data on causes of death. No significant difference in the mortality risk between in-patients and those attending private specialists was seen after stratifying by cause of death. The only exception to this finding was death from suicide. There was no difference in the risk of mortality between those attending out-patient services or private specialists, both being significantly lower than the risk for those who had ever been admitted (Table 5).

\section{Sensitivity analyses}

We found similar results when we used the entire population of Nova Scotia as the reference population rather than excluding those known to primary care or specialist psychiatric services. In this case, the resulting mortality rate ratios were 1.76 for males and 1.63 for females. We also found

Table 2 Mortality rate ratios by principal psychiatric diagnosis and gender

\begin{tabular}{|c|c|c|c|c|c|c|}
\hline & \multicolumn{3}{|c|}{ Males } & \multicolumn{3}{|c|}{ Females } \\
\hline & Psychiatric care & Primary care & All & Psychiatric care & Primary care & All \\
\hline & $\operatorname{MRR}(95 \% \mathrm{Cl})$ & MRR $(95 \% \mathrm{Cl})$ & MRR $(95 \% \mathrm{Cl})$ & MRR $(95 \% \mathrm{Cl})$ & MRR $(95 \% \mathrm{Cl})$ & MRR $(95 \% \mathrm{Cl})$ \\
\hline Dementia & $8.24(1.58-14.7)$ & $4.33(3.02-5.61)$ & $5.54(3.8 \mathrm{I}-7.22)$ & $5.63(3.7 \mathrm{I}-7.49)$ & $5.92(0.86-10.83)$ & $5.71(2.96-8.36)$ \\
\hline Alcohol/drug disorder & $2.66(2.04-3.26)$ & $1.42(1.23-1.62)$ & $1.58(1.38-1.76)$ & $2.67(1.55-3.75)$ & $1.06(0.73-1.37)$ & I.2I (0.89-I.5I) \\
\hline \multicolumn{7}{|l|}{ Functional psychosis } \\
\hline Schizophrenia & $2.47(1.74-3.64)$ & $2.21(0.55-3.83)$ & $2.24(1.58-2.88)$ & $2.39(I .35-3.4 I)$ & $2.52(0.96-4.03)$ & $2.16(1.5 I-2.79)$ \\
\hline Other psychosis & $4.29(3.70-4.87)$ & $4.44(3.76-5.09)$ & 4.51 (4.09-4.92) & $4.67(4.0 \mathrm{I}-5.3 \mathrm{I})$ & $5.26(4.56-5.93)$ & $5.56(5.07-6.03)$ \\
\hline \multicolumn{7}{|l|}{ Mood disorder } \\
\hline Affective psychosis & $2.14(I .87-2.4 I)$ & 1.61 (1.30-I.9I) & $1.96(1.78-2.13)$ & I.76 (I.54-I.98) & $\mathrm{I} .63$ (I.38-I.87) & I.7I (I.57-I.85) \\
\hline Depressive disorder & 2.47 (1.88-3.04) & $2.06(1.80-2.32)$ & $2.23(1.98-2.47)$ & $2.00(1.54-2.44)$ & 1.81 (1.59-2.02) & $1.99(1.78-2.20)$ \\
\hline Neurotic disorder & I.I6 (0.87-I.44) & 1.05 (I.00-I.10) & $1.10(1.05-1.14)$ & 1.47 (I.I8-I.76) & $0.89(0.84-0.93)$ & $0.95(0.91-0.99)$ \\
\hline Personality disorder & $2.28(1.29-3.25)$ & $1.13(0.34-1.90)$ & $2.04(1.27-2.79)$ & $2.17(0.49-3.80)$ & $2.05(0.80-3.28)$ & $2.08(1.10-3.04)$ \\
\hline Adjustment reaction & $2.30(1.92-2.68)$ & I.4I (I.08-I.74) & $1.92(1.57-2.26)$ & 1.61 (1.29-1.93) & I.II (0.84-I.38) & $1.44(1.16-1.72)$ \\
\hline Other mental disorder & $1.83(1.25-2.40)$ & $\mathrm{I} .43(\mathrm{I} .3 \mathrm{I}-\mathrm{I} .56)$ & $\mathrm{I} .46$ (I.33-I.57) & $2.66(1.65-3.63)$ & I.I5 (I.02-I.27) & $1.20(1.08-1.32)$ \\
\hline Non-specific diagnosis' & $3.29(2.94-3.63)$ & - & $3.29(2.94-3.63)$ & $3.02(2.7 I-3.33)$ & - & $3.02(2.7 \mathrm{I}-3.33)$ \\
\hline Total & $2.78(2.67-4.07)$ & I.54 (I.50-I.57) & I.80 (I.77-I.83) & $2.60(2.50-2.69)$ & I.43 (I.39-I.46) & $1.69(I .66-I .7 I)$ \\
\hline
\end{tabular}

MRR, mortality rate ratio.

I. Non-specific diagnoses outside of ICD-9 Chapter 5 were not included for patients who had only attended primary care. 


\begin{tabular}{|c|c|c|c|c|c|c|}
\hline & \multicolumn{3}{|c|}{ Males } & \multicolumn{3}{|c|}{ Females } \\
\hline & Psychiatric care & Primary care & All & Psychiatric care & Primary care & All \\
\hline & MRR $(95 \% \mathrm{Cl})$ & $\operatorname{MRR}(95 \% \mathrm{Cl})$ & $\operatorname{MRR}(95 \% \mathrm{Cl})$ & $\operatorname{MRR}(95 \% \mathrm{Cl})$ & $\operatorname{MRR}(95 \% \mathrm{Cl})$ & $\operatorname{MRR}(95 \% \mathrm{Cl})$ \\
\hline Malignant neoplasm & $1.85(1.67-2.02)$ & $1.73(1.66-1.79)$ & $\mathrm{I} .76(\mathrm{I} .70-\mathrm{I} .8 \mathrm{I})$ & $1.86(1.68-2.02)$ & $\mathrm{I} .39(1.32-1.44)$ & $1.50(1.44-1.54)$ \\
\hline Diabetes mellitus & $4.50(3.27-5.62)$ & $1.33(1.00-1.54)$ & $2.00(1.64-2.23)$ & $3.00(2.08-3.53)$ & I.3I (I.00-I.47) & $1.69(1.42-1.80)$ \\
\hline Acute myocardial infarction & $1.48(I .15-1.76)$ & $1.06(0.95-1.18)$ & $1.15(1.05-1.24)$ & $2.19(1.76-2.52)$ & I.2I (I.07-I.32) & $1.40(1.29-1.50)$ \\
\hline Other ischaemic heart disease & $2.52(2.19-2.86)$ & $\mathrm{I} .37(\mathrm{I} .26-\mathrm{I} .47)$ & $1.60(1.51-1.69)$ & $2.64(2.25-2.98)$ & $\mathrm{I} .40$ (I.27-I.5I) & $1.66(I .56-1.75)$ \\
\hline Cerebrovascular disease & $4.39(3.7 \mathrm{I}-4.85)$ & $\mathrm{I} .75(\mathrm{I} .56-\mathrm{I} .87)$ & $2.28(2.19-2.36)$ & $2.61(2.23-2.95)$ & $\mathrm{I} .63(\mathrm{I} .5 \mathrm{I}-\mathrm{I} .75)$ & $1.84(1.74-1.92)$ \\
\hline Other circulatory system disorder & $2.22(1.84-2.56)$ & $1.49(1.38-1.6 I)$ & $\mathrm{I} .64(\mathrm{I} .53-\mathrm{I} .73)$ & $2.43(2.13-2.72)$ & $\mathrm{I} .38(\mathrm{I} .29-\mathrm{I} .48)$ & $\mathrm{I} .60(\mathrm{I} .53-\mathrm{I} .69)$ \\
\hline Pneumonia and influenza & $3.67(2.96-4.28)$ & $1.78(1.60-1.97)$ & $2.15(2.00-2.31)$ & $3.75(3.17-4.29)$ & $\mathrm{I} .38(\mathrm{I} .20-\mathrm{I} .53)$ & $1.88(1.73-2.00)$ \\
\hline COPD & $3.45(2.92-3.98)$ & $\mathrm{I} .40$ (I.24-I.55) & $1.80(1.68-1.93)$ & $3.88(3.21-4.43)$ & $\mathrm{I} .42(\mathrm{I} .25-\mathrm{I} .6 \mathrm{I})$ & $1.96(1.79-2.07)$ \\
\hline Accidental death & 2.37 (1.84-2.83) & I.37 (I.I2-I.55) & $\mathrm{I} .63$ (I.44-I.79) & 2.21 (1.58-2.87) & $1.36(1.08-1.60)$ & 1.64 (I.50-I.87) \\
\hline Suicide & $8.08(7.60-9.08)$ & $1.75(1.40-2.08)$ & $3.58(3.50-3.85)$ & $8.00(7.00-10.00)$ & $1.50(1.00-2.50)$ & $3.00(4.00-4.50)$ \\
\hline Other cause of death & 4.27 (3.99-4.54) & $1.76(1.68-1.83)$ & $2.28(2.22-2.34)$ & $3.41(3.18-3.63)$ & $1.69(1.62-1.76)$ & $2.06(2.00-2.11)$ \\
\hline Missing cause of death & $2.05(1.72-2.31)$ & I.I4 (I.02-I.22) & I.34 (I.24-I.4I) & 1.95 (1.68-2.22) & $\mathrm{I} .13$ (I.04-I.22) & I.3I (I.24-I.40) \\
\hline Total & $2.78(2.67-2.88)$ & I.54 (I.50-I.57) & I.80 (I.77-I.83) & $2.60(2.50-2.69)$ & $\mathrm{I} .43(1.39-1.46)$ & $1.69(I .66-1.7 I)$ \\
\hline
\end{tabular}

COPD, chronic obstructive pulmonary disease; MRR, mortality rate ratio.

similar results when we excluded nonChapter 5 diagnoses from the analysis (data supplement to the online version of this paper, Table 11).

\section{DISCUSSION}

\section{Strengths of the study}

One in five Canadians has a psychiatric disorder and so the increased mortality rate in this population is a major public health concern (Health Canada, 2002). Most studies have concentrated on the mortality rate among psychiatric in-patients and not considered those seen in hospital outpatient clinics, private specialists' offices or primary care centres, where the vast majority of patients receive treatment. Only two previous studies have compared outpatient and in-patient rates in specialist settings using the same methodology, one from Australia (Lawrence et al, 2000) and the other from Italy (Amaddeo et al, 1995). In the Australian study, only inpatients and those out-patients who were seen in public hospital settings were included (Lawrence et al, 2000). Patients who were seen by private psychiatrists in the community or by general practitioners could not be included. In the Italian study, all patients seen by specialists as in-patients or out-patients were included, but not those in primary care (Amaddeo et al, 1995).
Neither of these countries offers universal healthcare that is free at the point of delivery, as is the case in Canada. In theory this universal access to medically necessary care should decrease the effect of psychiatric status on health outcomes. To our knowledge, this is the first study to measure the mortality rate of all individuals with a treated psychiatric disorder, irrespective of setting, and including primary care, so reducing referral or selection bias. The only patients we were unable to include were those attending private psychologists or other non-medically qualified mental health professionals in private practice.

\section{Limitations of the study}

Although we included patients in all medical and psychiatric settings, we could not control for differences in help-seeking behaviour, or recognition of psychiatric morbidity by the professional of first contact. Neither could we study the effect of lifestyle, such as alcohol or tobacco use. There are other limitations to the study. We used routinely collected administrative data that may be subject to recording bias, particularly in general practice. Although there is good evidence for the validity of the Discharge Abstract Database, information on other administrative data is more limited (Kephart et al, 2003). Unlike previous Australian and Italian studies of in-patients and out-patients (Amaddeo et al, 1995; Lawrence et al, 2000), we did not have data on marital status, length of time since first contact with services and educational status, all of which might influence mortality. We were therefore unable to adjust for these factors in the Cox regression. We were also unable to consider the effect of legal status. However, two studies from Australia and the USA showed no difference in the mortality rates between involuntary and voluntary patients (Amaddeo et al, 1995; Crisanti \& Love, 1999). In spite of the high mortality rate there were few deaths in some subgroups with insufficient power to detect statistically significant effects.

Our inception cohort method meant that we only considered patients in the first 5 years of treatment for a psychiatric disorder. However, previous work has indicated that the majority of excess mortality occurs within the first 7 years of psychiatric treatment (Lawrence et al, 2000). The only exception to this finding is schizophrenia, for which the observed and expected mortality curves for patients continue to diverge over 15 years, and could mean that our study underestimated the effect of schizophrenia on mortality.

As this was an epidemiological study of routinely collected administrative data, we 
Table 4 Mortality risk factors

\begin{tabular}{|c|c|c|}
\hline Variable & $\begin{array}{c}\text { Adjusted } \\
\text { RR }\end{array}$ & $95 \% \mathrm{Cl}$ \\
\hline \multicolumn{3}{|l|}{ Diagnosis } \\
\hline Neurotic disorder & 1.000 & \\
\hline Dementia & 2.057 & $1.925-2.198$ \\
\hline $\begin{array}{l}\text { Alcohol or drug } \\
\text { disorder }\end{array}$ & 1.489 & I.328-I.670 \\
\hline \multicolumn{3}{|l|}{ Functional psychosis } \\
\hline Schizophrenia & 1.526 & $1.227-1.899$ \\
\hline Other psychosis & 2.729 & $2.550-2.922$ \\
\hline \multicolumn{3}{|l|}{ Mood disorder } \\
\hline Affective psychosis & 1.348 & $1.238-1.467$ \\
\hline Depressive disorder & 1.886 & I.719-2070 \\
\hline Personality disorder & 1.614 & $1.216-2.143$ \\
\hline Adjustment reaction & 1.522 & I.319-1.757 \\
\hline Other mental disorder & 1.290 & I.I87-I.40 I \\
\hline Non-specific diagnosis & $\mathrm{I} .458$ & $1.030-2.064$ \\
\hline \multicolumn{3}{|l|}{ Gender } \\
\hline Female & 1.000 & \\
\hline Male & 1.743 & $1.67 \mid-1.818$ \\
\hline Age (increase per decade) & 2.338 & $2.302-2.374$ \\
\hline \multicolumn{3}{|l|}{ Income quartile' } \\
\hline$\$ 48746-\$ 225642$ & 1.000 & \\
\hline$\$ 40088-\$ 48746$ & 1.145 & $1.064-1.232$ \\
\hline$\$ 33803-\$ 40088$ & 1.185 & I.100-I.276 \\
\hline$\$ 11786-\$ 33803$ & 1.235 & I.152-I.325 \\
\hline \multicolumn{3}{|l|}{ Place of residence } \\
\hline Non-metropolitan area & 1.000 & \\
\hline Metropolitan area & 0.965 & $0.920-1.01 \mathrm{I}$ \\
\hline \multicolumn{3}{|l|}{ Treatment setting } \\
\hline Primary care & 1.000 & \\
\hline Private specialist & 1.573 & I.468-I.685 \\
\hline $\begin{array}{l}\text { Mental health out- } \\
\text { patient }\end{array}$ & 1.262 & I.187-I.342 \\
\hline In-patient & 1.531 & I.372-I.707 \\
\hline
\end{tabular}

RR, relative risk.

I. Canadian dollars.

relied on ICD-9 diagnoses. Diagnostic accuracy was improved through the clinical use of DSM diagnoses, which are then converted to ICD-9 codes, as well as DSM training courses. However, clinicians outside publicly funded facilities do not have access to DSM training. Finally, as this was a study of mortality irrespective of cause, we did not include comorbid physical illness as a covariate in our regression models. However, we plan to study this interaction and its effect on a range of outcomes, including initial admission to hospital and entry on to the cancer registry.

Table 5 Mortality risk factors for selected causes of death

\begin{tabular}{|c|c|c|c|c|}
\hline \multirow[t]{2}{*}{ Variable } & \multicolumn{2}{|c|}{ Myocardial infarction } & \multicolumn{2}{|c|}{ Suicide } \\
\hline & Adjusted RR & $95 \% \mathrm{Cl}$ & Adjusted RR & $95 \% \mathrm{Cl}$ \\
\hline \multicolumn{5}{|l|}{ Diagnosis } \\
\hline Neurotic disorder & 1.000 & & 1.000 & \\
\hline Dementia & 1.078 & $0.794-1.465$ & 0.418 & $0.097-1.802$ \\
\hline Alcohol or drug disorder & 1.487 & $0.883-2.504$ & 2.106 & $1.26-3.519$ \\
\hline \multicolumn{5}{|l|}{ Functional psychosis } \\
\hline Schizophrenia & $1.57 \mid$ & $0.629-3.924$ & 0.386 & $0.091-1.643$ \\
\hline Other psychosis & 1.702 & $1.254-2.31$ & 0.400 & $0.095-1.679$ \\
\hline \multicolumn{5}{|l|}{ Mood disorder } \\
\hline Affective psychosis & 1.000 & $0.674-1.486$ & $1.75 \mathrm{I}$ & $1.098-2.792$ \\
\hline Depressive disorder & 2.079 & $1.438-3.006$ & 1.958 & $0.925-4.144$ \\
\hline Personality disorder & $\mathrm{I} .194$ & $0.295-4.832$ & 3.020 & I.263-7.22 \\
\hline Adjustment reaction & 0.970 & $0.454-2.070$ & 0.432 & $0.104-1.787$ \\
\hline Other mental disorder & 1.561 & I.134-2.147 & 0.627 & $0.302-1.299$ \\
\hline Non-specific diagnosis & 2.003 & $0.483-8.312$ & 0.000 & $0.000-0.000$ \\
\hline \multicolumn{5}{|l|}{ Gender } \\
\hline Female & 1.000 & & 1.000 & \\
\hline Male & 1.719 & $1.423-2.077$ & 1.728 & $1.657-1.802$ \\
\hline Age (increase per decade) & 2.824 & $2.622-3.043$ & $\mathrm{I} .158$ & $1.058-1.268$ \\
\hline \multicolumn{5}{|l|}{ Income quartile' } \\
\hline$\$ 48746-\$ 225642$ & 1.000 & & 1.000 & \\
\hline$\$ 40088-\$ 48746$ & $\mathrm{I} .124$ & $0.81 \mathrm{I}-1.56$ & 1.411 & $0.838-2.376$ \\
\hline$\$ 33803-\$ 40088$ & 1.524 & $1.097-2.119$ & 1.166 & $0.672-2.023$ \\
\hline$\$ 11786-\$ 33803$ & 1.575 & I.I4I-2.I75 & 1.033 & $0.587-1.817$ \\
\hline \multicolumn{5}{|l|}{ Place of residence } \\
\hline Non-metropolitan area & 1.000 & & 1.000 & \\
\hline Metropolitan area & 1.14 & $0.93-1.399$ & 0.888 & $0.614-1.284$ \\
\hline \multicolumn{5}{|l|}{ Treatment setting } \\
\hline Primary care & 1.000 & & 1.000 & \\
\hline Private specialist & 1.950 & $1.440-2.640$ & 2.368 & $1.299-4.315$ \\
\hline Mental health out-patient & $\mathrm{I} .143$ & $0.843-1.549$ & 3.001 & $|.89|-4.763$ \\
\hline In-patient & $1.56 \mathrm{I}$ & $0.914-2.669$ & 16.534 & $10.189-26.83 \mid$ \\
\hline
\end{tabular}

RR, relative risk.

I. Canadian dollars.

\section{Comparisons with other studies}

In common with studies restricted to patients of psychiatric services (Amaddeo et al, 1995; Harris \& Barraclough, 1998; Lawrence et al, 2000; Hannerz et al, 2001; Hansen et al, 2001; Rasanen et al, 2003; Vythilingam et al, 2003) or primary care (Ensinck et al, 2002), our study of all patients in treatment for psychiatric disorder showed they had an increased mortality rate. Although the rate for patients of specialist psychiatric services was particularly high, we also found an increased mortality rate for patients in primary care. As expected, mortality rates were elevated for a wide range of causes of death, including carcinoma, diabetes, cardiovascular disease, respiratory disease, and infections (Brown et al, 2000; Lawrence et al, 2000; Hansen et al, 2001).

Our findings mirror those of a comparable study from Western Australia that used the same methodology on a similar administrative database (Lawrence et al, 2000). Findings for individual psychiatric disorders were also similar, with the highest rates being found for organic psychiatric disorders such as dementia (Black, 1998; Lawrence et al, 2000; Hansen et al, 2001). However, our mortality rate for out-patients was higher than that in the Western Australian study. One explanation might be that we were unable to analyse 
data on residents of psychiatric hostels separately from other out-patients; the Australian study showed that their mortality rates were as high as those of in-patients (Lawrence et al, 2000). Another difference was that the Australian study only considered the public sector, and so the mortality rate for patients of private specialists is unknown. Another explanation is that our data include private specialists who see a relatively high proportion of patients with severe mental illness. Thirty four per cent of patients seen by specialists in Nova Scotia have schizophrenia or non-affective psychosis, as opposed to $24 \%$ of outpatients in publicly funded facilities and $5 \%$ of those in primary care.

In the case of patients attending their general practitioner, we were generally only able to compare our rates for depression. These were similar to those seen in general practice in The Netherlands (Ensinck et al, 2002). Our rates are also similar to those reported in community surveys of people with depression, including the Stirling County Survey in Atlantic Canada (Cuijpers \& Smit, 2002). We are aware of only one community study that investigated the effect of other mental disorders on mortality (Joukamaa et al, 2001). As in our sample of general practice attenders, functional psychoses and mood disorders were associated with an elevated mortality risk, whereas neuroses were not. This study did not include organic, adjustment or personality disorders.

The results suggest that the mortality risk of patients with psychiatric disorders in general practice is similar to that of the community and that, although higher than in people without psychiatric morbidity, it is less than those in contact with specialist psychiatric services. However, in terms of absolute figures, 6413 out of 8917 deaths $(72 \%)$ occurred in patients who had only attended general practice.

\section{Explanations for increased mortality}

There are a number of possible contributing factors for this elevated risk of mortality, especially in patients attending specialist psychiatric services. Patient-based factors include neurological or immunological pathology, adherence to treatment, alcohol and tobacco use, diet, self-care and exercise (Brown et al, 2000; Lawrence et al, 2000; Cuijpers \& Smit, 2002; Lambert et al, 2003). Other possible

\section{CLINICAL IMPLICATIONS}

- The increased risk of mortality is an issue for all patients with mental illness, including individuals seen only in primary care, not just those who have received psychiatric in-patient treatment.

Although the mortality risk is lower in patients of general practitioners than of specialists, the greatest absolute number of deaths occurred in the former group.

- The physical health of people with psychiatric illness should be kept under constant surveillance in all treatment settings, including primary care.

\section{LIMITATIONS}

- We relied on routine administrative data that might have been subject to recording bias.

- There might have been additional influences on mortality, such as marital status, length of time since first contact with services and educational status, that we could not control for in the analysis.

- As this was an epidemiological study, detailed clinical information or information on risk factors such as smoking was not available.

STEPHEN KISELY, MD, MSc, Department of Psychiatry, Dalhousie University and Health Outcome Unit, Capita District Health Authority, Halifax; MARK SMITH, BSc, Population Health Research Unit, Dalhousie University, Halifax, Canada; DAVID LAWRENCE, PhD, Centre for Developmental Health, Curtin University of Technology, Telethon Institute for Child Health Research, Perth, Australia; SARAH MAATEN, MSc, Population Health Research Unit, Dalhousie University, Halifax, Canada

Correspondence: Dr Stephen Kisely, Dalhousie University, Abbie J. Lane Memorial Building, 5909 Veteran's Memorial Lane, Suite 92II, Halifax, Nova Scotia B3H 2E2, Canada. Tel. + I 9024737356 ; fax + I 902473 4887; e-mail: Stephen.Kisely@cdha.nshealth.ca

(First received 14 September 2004, final revision 27 January 2005, accepted 4 February 2005)

explanations are cardiovascular and endocrine side-effects of psychotropic medication, reduced access to general medical care, the perception by specialist psychiatrists that physical health should be the province of referring doctors, and the increased difficulty in recognising physical comorbidity in psychiatric patients with physical complaints (Brown et al, 2000; Lawrence et al, 2000; Hansen et al, 2001; Cuijpers \& Smit, 2002; Vanina et al, 2002; Elming et al, 2003). Although authors have also suggested that suicide and accidental death may be an explanation for increased mortality (Cuijpers \& Smit, 2002), our study suggests that this risk is higher for all causes of death.

Our findings support an association between psychiatric disorder and mortality from carcinoma, although this is one cause of death not uniformly associated with increased mortality in psychiatric patients (Cohen et al, 2002). Lawrence et al
(2000), using the same methodology as ours, also reported a significantly higher mortality from carcinoma, even though the incidence rate was no higher than that of the general population. This suggests that psychiatric patients benefit less from cancer services, either because of problems with access or adherence to treatment.

\section{Implications}

Strategies to reduce mortality in psychiatric patients include addressing lifestyle and access to services, as well as monitoring the physical health of both in-patients and out-patients. Given that we have shown that mortality risk is increased across a wide range of psychiatric disorders, efforts should not be restricted to patients with dementia or psychosis. Similarly, although the relative risk is lower than in specialist settings, most deaths occurred in patients who had only attended their general 
practitioner for psychiatric care, suggesting the inclusion of primary care in initiatives to reduce mortality risk.

\section{ACKNOWLEDGEMENT}

This study was supported by a development grant from the Nova Scotia Health Research Foundation.

\section{REFERENCES}

Amaddeo, F., Bisoffi, G., Bonizzato, P., et al (1995) Mortality among patients with psychiatric illness. A tenyear case register study in an area with a communitybased system of care. British Journal of Psychiatry, 166 783-788.

American Psychiatric Association (1994) Diagnostic and Statistical Manual of Mental Disorders (4th edn) (DSM-IV). Washington, DC: APA.

Black, D.W. (1998) lowa record-linkage study: death rates in psychiatric patients. Journal of Affective Disorders, 50, 277-282.

Brown, S., Barraclough, B. \& Inskip, H. (2000) Causes of the excess mortality of schizophrenia. British Journal of Psychiatry, 177, 212-217.

\section{Bruce, M. L., Leaf, P. J., Rozal, G. P., et al (1994)}

Psychiatric status and 9-year mortality data in the New Haven Epidemiologic Catchment Area Study. American Journal of Psychiatry, 15I, 716-72I.

Clottey, C., Mo, F., LeBrun, B., et al (200I) The development of the National Diabetes Surveillance System (NDSS) in Canada. Chronic Diseases in Canada, 22, 67-69.

Cohen, M., Dembling, B. \& Schorling, J. (2002) The association between schizophrenia and cancer: a population-based mortality study. Schizophrenia Research, 57, 139-146.

Crisanti, A. S. \& Love, E. J. (1999) Mortality among involuntarily admitted psychiatric patients: a survival analysis. Social Psychiatry and Psychiatric Epidemiology, 34, 627-633.

Cuijpers, P. \& Smit, F. (2002) Excess mortality in depression: a meta-analysis of community studies. Journal of Affective Disorders, 72, 227-236.

Elming, H., Sonne, J. \& Lublin, H. K. (2003) The importance of the QT interval: a review of the literature. Acta Psychiatrica Scandinavica, 107, 96-101.

Ensinck, K. T., Schuurman, A. G., van den Akker, M., et al (2002) is there an increased risk of dying after depression? American Journal of Epidemiology, 156, 1043-1048.

Hannerz, H., Borga, P. \& Borritz, M. (200I) Life expectancies for individuals with psychiatric diagnoses. Public Health, II5, 328-337.

Hansen, V., Jacobsen, B. K. \& Arnesen, E. (200I) Cause-specific mortality in psychiatric patients after deinstitutionalisation. British Journal of Psychiatry, $\mathbf{1 7 9}$, 438-443.

Harris, E. C. \& Barraclough, B. (1998) Excess mortality of mental disorders. British Journal of Psychiatry, 173, II-53.

Health Canada (2002) A Report on Mental Illnesses in Canada. Ottawa: Health Canada.

Joukamaa, M., Heliövaara, M., Knekt, P., et al (200I) Mental disorders and cause-specific mortality. British Journal of Psychiatry, 179, 498-502.

Kapral, M., Wang, H., Mamdani, M., et al (2002) Effect of socioeconomic status on treatment and mortality after stroke. Stroke, 33, 268-275.

Kephart, G., Casey, J., Ranger, R., et al (2003) The Development and Validation of an Alternative Case Definition for the National Diabetes Surveillance System Report to the Data Validation Working Group, National Diabetes Surveillance System. Health Canada. Halifax: Population Health Research Unit, Dalhousie University.

Lambert, T. J. R., Velakoulis, S. \& Pantelis, C. (2003) Medical comorbidity in schizophrenia. Medical Journal of Australia, 178, S67-S70.
Lawrence, D., Jablensky, A. V., Holman, C. D., et al (2000) Mortality in Western Australian psychiatric patients. Social Psychiatry and Psychiatric Epidemiology, 35, 34I-347

Lawrence, D. M., Holman, C. D. J., Jablensky, A.V., et al (2003) Death rate from ischaemic heart disease in Western Australian psychiatric patients 1980-1998. British Journal of Psychiatry, 182, 31-36.

Mulsant, B. H. \& Ganguli, M. (1999) Epidemiology and diagnosis of depression in late life. Journal of Clinical Psychiatry, 60, 9-15.

Newman, S. C. \& Bland, R. C. (1991) Mortality in a cohort of patients with schizophrenia: a record linkage study. Canadian Journal of Psychiatry, 36, 239-245.

Ontario Hospital Association, Ontario Ministry of Health \& Hospital Medical Records Institute (1991) Report of the Ontario Data Quality Reabstracting Study. Ontario: Ontario Hospital Association.

Ostbye, T., Hill, G. \& Steenhuls, R. (1999) Mortality in elderly Canadians with and without dementia: a 5-year follow-up. Neurology, 53, 521-526.

Rasanen, S., Hakko, H., Viilo, K., et al (2003) Excess mortality among long-stay psychiatric patients in Northern Finland. Social Psychiatry and Psychiatric Epidemiology, 38, 297-304

Strom, B. L. (2001) Data validity using claims data. Pharmacoepidemiology and Drug Safety, 10, 389-839.

Vanina, Y., Podolskaya, A., Sedky, K., et al (2002) Body weight changes associated with psychopharmacology. Psychiatric Services, 53, 842-847.

Vythilingam, M., Chen, J., Bremner, J. D., et al (2003) Psychotic depression and mortality. American Journal of Psychiatry, 160, 574-576.

Williams, J. L. \& Young, W. (1996) Inventory of Studies on the Accuracy of Canadian Health Administrative Databases (96-03-TR). Toronto: Institute for Clinical Evaluative Sciences in Ontario.

World Health Organization (1978) International Statistical Classification of Diseases and Related Health Problems (ICD-9). Geneva: WHO. 